\title{
Strain hardening behavior of lightweight hybrid polyvinyl alcohol (PVA) fiber reinforced cement composites
}

\author{
Shaikh Faiz Uddin Ahmed • Hirozo Mihashi
}

Received: 1 June 2009/Accepted: 8 November 2010

(C) RILEM 2010

\begin{abstract}
Experimental results on the strain hardening and multiple cracking behaviors of polyvinyl alcohol (PVA) fiber reinforced cementitious composites under bending are reported in this paper. Different hybrid combinations of PVA fibers with different lengths and volume fractions are considered to reinforce the mortar matrix. Among different hybrid combinations, the composite containing $2 \%$ thicker PVA fibers of $12 \mathrm{~mm}$ length and $1 \%$ thinner PVA fibers of $6 \mathrm{~mm}$ length and the composite containing 2\% thicker PVA fibers of $24 \mathrm{~mm}$ length and $1 \%$ thinner PVA fibers of $6 \mathrm{~mm}$ length showed the best performance in terms of highest ultimate load, largest CMOD (crack mouth opening displacement) at peak load and multiple cracking behavior. The effects of four types of light weight sands on the strain hardening and multiple cracking behavior of hybrid fiber composites are also evaluated in this study. It has been observed that the ultimate load and CMOD at peak load for all light weight hybrid fiber composites are almost the same irrespective of volume fractions of light weight sand. The composites containing finer light weight sands exhibited higher ultimate load than those containing coarser
\end{abstract}

\section{S. F. U. Ahmed ( $\square)$}

Department of Civil Engineering, Curtin University,

Perth, Australia

e-mail: shaikhfa@rocketmail.com

H. Mihashi

Tohoku Institute of Technology, Sendai, Japan light weight sands. It is also observed that the hybrid fiber composite containing normal silica sand exhibited higher ultimate load than the composites with light weight sands.

Keywords Hybrid fibers - PVA - Strain hardening Multiple cracking $\cdot$ Light weight sand

\section{Introduction}

Recently, high performance fiber reinforced cementitious composites have been steadily developed. Among cementitious composites, short random fiber reinforcement with fiber content between 2 and 3 volume percent appears to be the most attractive due to ease of processing. The addition of short random fibers increases the toughness and/or energy absorption capacity and a possible increase in ultimate strength and/or strain capacity of cementitious composite. In conventional fiber reinforced concrete (FRC), where both fine and coarse aggregates are included, the toughening effect is limited to the postpeak region of the load-deformation curve. Fiber reinforced cementitious composites (FRCC) with strain hardening and multiple cracking behavior in uniaxial tension and bending are also developed. In FRCC matrices are mainly cement paste or mortar. The unique feature of a cementitious composite exhibiting strain hardening and multiple cracking behaviors is the increase of the composite's post- 
cracking strength beyond its first crack strength accompanied by the development of closely spaced multiple cracks. Past research works indicate that strain hardening was mostly achieved in FRCC containing mono fibers [1-6]. Recently, hybrid fiber FRCC exhibiting strain hardening and multiple cracking behaviors have also been developed [7-10].

In hybrid fiber composites, two or more different types of fibers are suitably combined to exploit their unique properties. The hybridization of fibers in FRCC can be done in different ways, such as by combining different lengths, modulus and tensile strengths of fibers. Large macro fibers bridge the big cracks and provide post-peak ductility, while small micro fibers bridge the micro cracks and enhance the response prior or just after the cracking [11]. Micro fibers also improve the pull out response of macro fibers, thus producing composites with high strength and toughness [12]. A hybrid fiber composite, with proper volume ratio of high and low modulus fibers, is expected to exhibit simultaneous improvement in ultimate strength, strain capacity and crack width properties [7, 10]. The hybrid fiber composites reported in the literature are mostly based on the hybrid combination of high and low modulus fibers in different volume fractions [7, 8, 10, 13-18]. Hybrid combination of different types of high modulus fibers [19] and low modulus fibers [20] in different lengths and volume fractions are also reported. Among different low modulus fibers, PVA fibers are high performance structural reinforcement fibers and have exhibited promising results in terms of higher tensile strain capacity, energy absorption and crack bridging properties $[1,3]$. PVA fibers are well suited for a wide variety of applications because of their high resistance to alkali, UV, chemicals, fatigue and abrasion.

In this paper, the feasibility of using two different types of PVA fibers in different lengths and volume fractions in the development of hybrid fiber composites are presented. Experimental results on the strain hardening and multiple cracking behavior of hybrid fiber composites reinforced with two different types of PVA fibers under bending are reported. The two PVA fibers used are of different length, diameter, tensile strength and modulus. Three point bending tests are carried out on notched specimens to obtain the load-crack mouth opening displacement (CMOD) response for mono and hybrid PVA fiber reinforced cementitious composites. Effects of different types of light weight sands and volume fractions on the strain hardening and multiple cracking behavior of hybrid fiber composites are also evaluated in the study.

\section{Experimental program}

The experimental program is divided into two parts. In the first part of the experimental program, two different types of PVA fibers (i.e. thinner and thicker) of different lengths and volume fractions were used to reinforce the mortar matrix. Diameters of thinner and thicker PVA fibers were $0.04 \mathrm{~mm}$ and $0.10 \mathrm{~mm}$, respectively. The normal fine silica sand was used in the mortar matrix. After having selected the hybrid fiber composites showing the best results among different hybrid combinations, subsequent experiments were based on these mixes of the hybrid composites. In the second part of the experiment, the effects of different types of light weight sands in different volume fractions were studied on the best hybrid fiber composites obtained from the first part of this study.

\section{Materials and mix proportions}

Table 1 shows the mix proportions for mono and hybrid fiber composites containing normal sand. Series 1 and 2 are for mono fiber composites containing thinner and thicker PVA fibers, respectively. Series 3 and 4 are for hybrid PVA fiber composites containing $12 \mathrm{~mm}$ long thicker PVA fibers together with 6,8 , and $12 \mathrm{~mm}$ long thinner PVA fibers, while series 5 and 6 are for hybrid fiber composites containing $24 \mathrm{~mm}$ long thicker PVA fibers together with 6, 8, and $12 \mathrm{~mm}$ long thinner PVA fibers. For each series, three prismatic notch specimens of $40 \times 40 \times 160 \mathrm{~mm}$ in dimension were cast. All specimens were demolded after $24 \mathrm{~h}$ of casting and kept under water for approximately 7 days. All specimens were tested in three-point bending using an Instron testing machine under displacement control with a loading rate of $0.4 \mathrm{~mm} / \mathrm{min}$. A schematic of the bending test setup is shown in Fig. 1.

Uniform dispersion of fibers is vital to the development of cementitious composites which effectively take advantage of reinforcement properties of fibers. Cellulose powder was used to facilitate uniform fiber dispersion. It acts as a colloidal 
Table 1 Mix proportions of mono and hybrid fiber composites containing normal silica sand used in the first part of this study

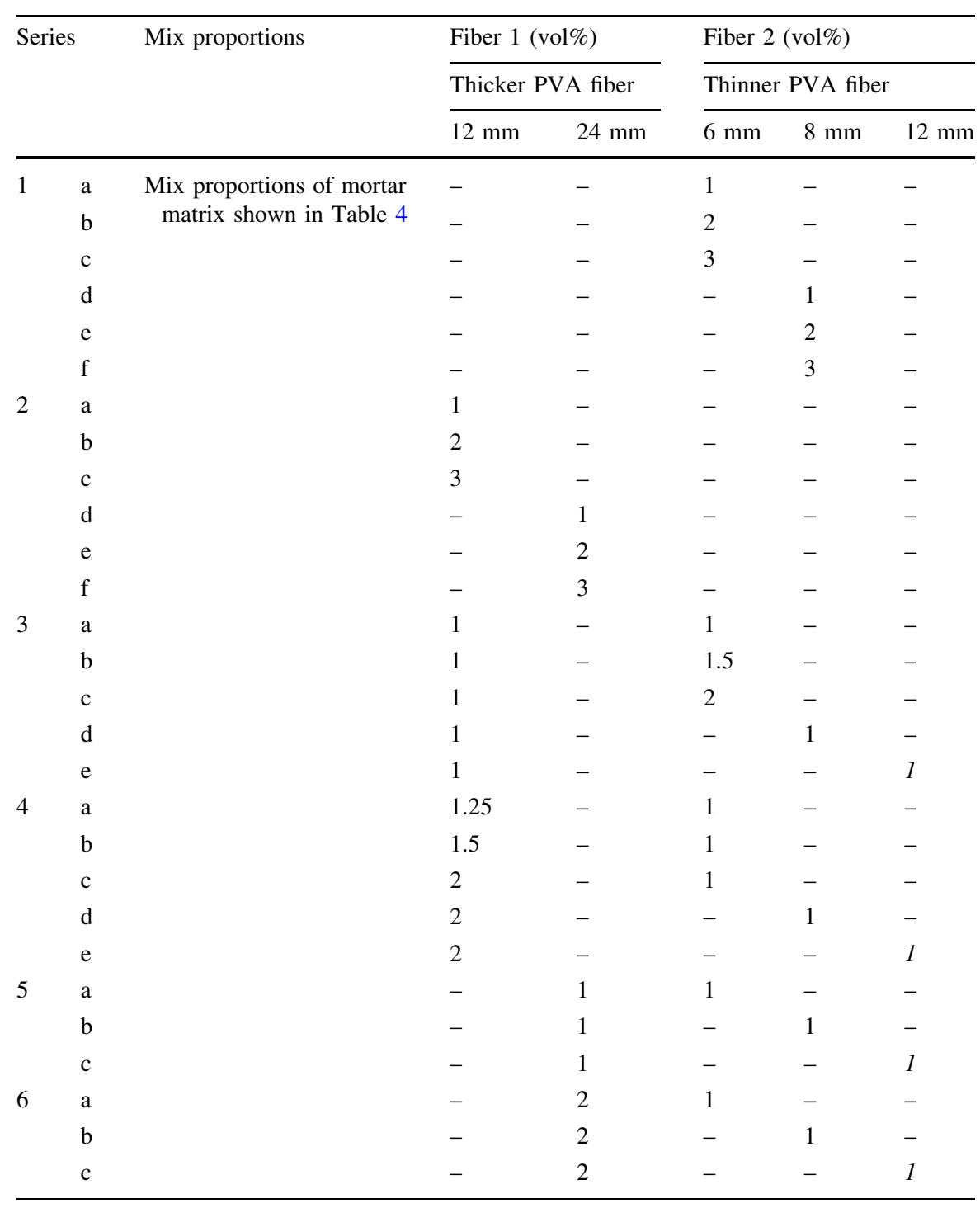

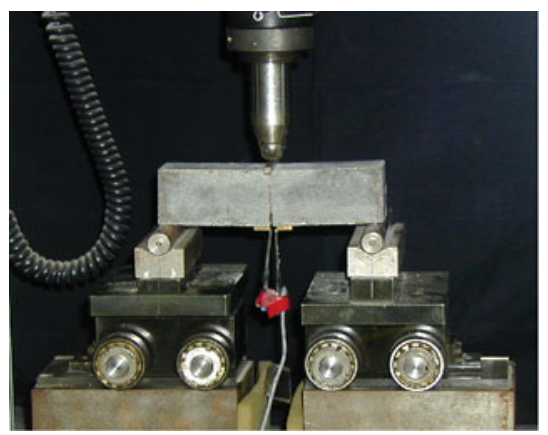

Fig. 1 Setup and detailing of the three-point bending tests

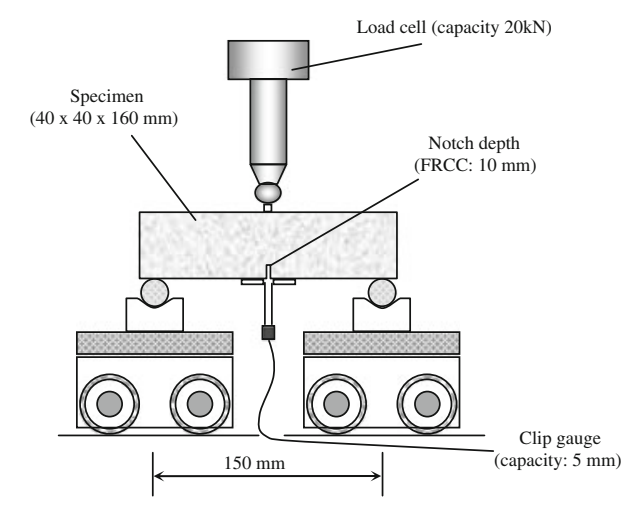




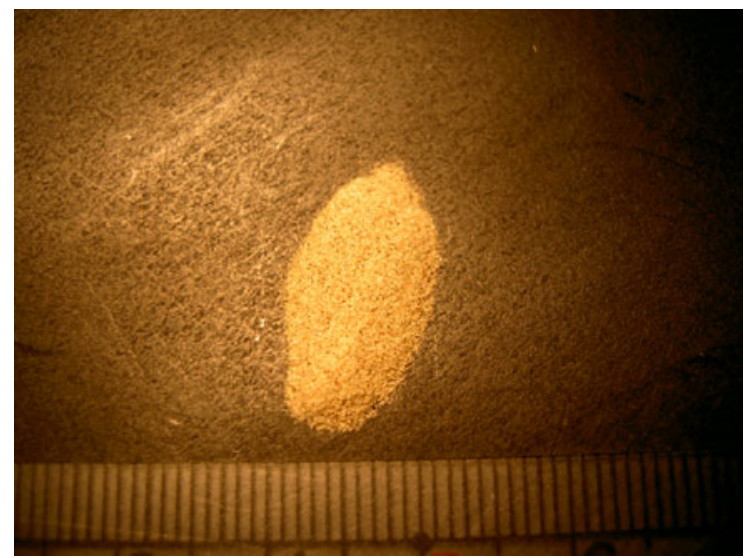

Fig. 2 Normal silica sand $(d=0.11 \mathrm{~mm})$

stabilizer and controls the rheology of the fresh mix. The mortar matrix of this study consisted of ordinary Portland cement and normal fine silica sand (Fig. 2). Four different types of light weight sands were also used in this study. The properties of normal silica sand and light weight sands (Fig. 3) are given in Table 2. The properties of polyvinyl alcohol (PVA) fibers are shown in Table 3. The mix proportions for the mortar matrix containing normal silica sand and light weight sand are given in Tables 4 and 5, respectively.
The mono and hybrid fiber composites containing normal silica sand and light weight sands were manufactured in an omni mixer. The mixing procedure is described in the following:

1. First ordinary Portland cement, cellulose powder and normal sand were dry mixed for $1 \mathrm{~min}$.

2. Then water was added and mixed for another 3 min.

3. The fibers were then added and mixed for another $5 \mathrm{~min}$.

In case of hybrid fiber composites containing light weight sands similar procedure was adopted.

\section{Results and discussions}

\subsection{Rheology of fresh mixes}

The workability and air content of fresh mixes of hybrid fiber composites containing normal silica sand and light weight sands are shown in Tables 6 and 7 , respectively. A reduction in flow value with an increase in the volume fraction of long fibers (such as fibers of 12 and $24 \mathrm{~mm}$ length) in hybrid fiber composites can be noted and is well accepted. The effect of light weight sands in the fresh properties of
Fig. 3 Light weight sand: a Type $\mathrm{V}$

$(d=0.005-0.15 \mathrm{~mm})$,

b Type OB0

$(d=0.6 \mathrm{~mm}), \mathbf{c}$ Type OB1

$(d=0.6-1.2 \mathrm{~mm})$,

d Type OB2

$(d=1.2-2.5 \mathrm{~mm})$
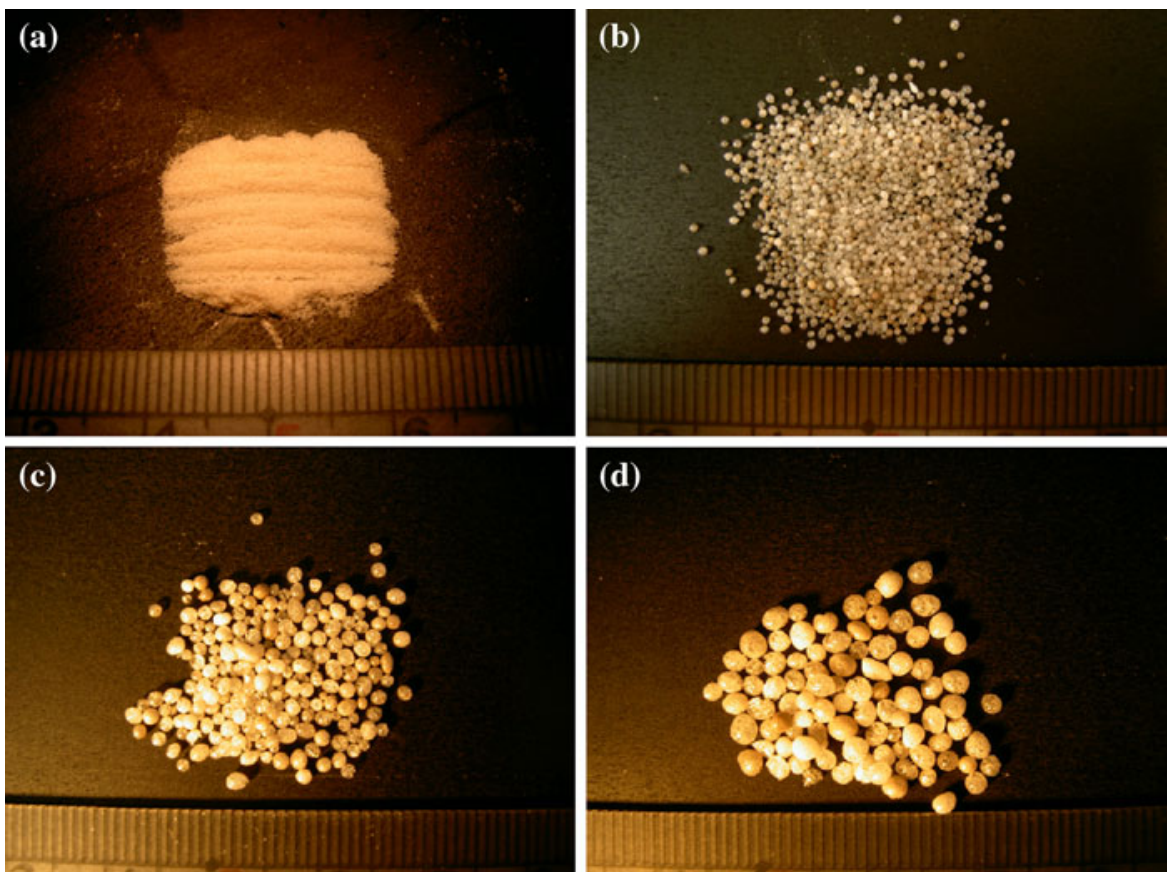
Table 2 Properties of normal sand and light weight sand

${ }^{\text {a }}$ Maximum size

Table 3 Properties of PVA fibers

\begin{tabular}{lllll}
\hline Sand & Types & $\begin{array}{l}\text { Size of sand } \\
\text { grain: d }(\mathrm{mm})\end{array}$ & $\begin{array}{l}\text { Unit weight } \\
\left(\mathrm{gm} / \mathrm{cm}^{3}\right)\end{array}$ & Source \\
\hline $\begin{array}{l}\text { Normal silica sand } \\
\text { Light weight sand }\end{array}$ & - & $0.11^{\mathrm{a}}$ & 2.61 & - \\
Finer & $\mathrm{V}$ & $0.005-0.15$ & 0.29 & Volcanic powder \\
& OB0 & $0.6^{\mathrm{a}}$ & 0.675 & Powder of \\
Coarser & OB1 & $0.6-1.2$ & 0.22 & OBSIDIAN rock \\
& OB2 & $1.2-2.5$ & 0.11 & \\
\hline
\end{tabular}

\begin{tabular}{lllllc}
\hline Types & $\begin{array}{l}\text { Length } \\
(\mathrm{mm})\end{array}$ & $\begin{array}{l}\text { Diameter } \\
(\mathrm{mm})\end{array}$ & $\begin{array}{l}\text { Modulus of } \\
\text { elasticity }(\mathrm{MPa})\end{array}$ & $\begin{array}{l}\text { Fiber strength } \\
(\mathrm{MPa})\end{array}$ & $\begin{array}{l}\text { Elongation } \\
(\%)\end{array}$ \\
\hline Thinner & 6,8 and 12 & 0.04 & 40,000 & 1600 & 6 \\
Thicker & 12,24 & 0.1 & 25,000 & 1100 & 10 \\
\hline
\end{tabular}

Table 4 Mix proportion of mortar matrix containing normal sand

\begin{tabular}{lllll}
\hline \multicolumn{4}{l}{ Mix proportions (by } & wt $\%)$ \\
\hline Cement & Water & Sand & Water/cement & Sand/cement \\
\hline 1.0 & 0.62 & 0.4 & 0.62 & 0.4
\end{tabular}

Note: Cellulose powder of $1.4 \%$ by weight of water was used in the mix

Table 5 Mix proportion of mortar matrix containing light weight sands

\begin{tabular}{lll}
\hline $\begin{array}{l}\text { Cement } \\
(\text { wt } \%)\end{array}$ & $\begin{array}{l}\text { Water } \\
(\text { wt } \%)\end{array}$ & $\begin{array}{l}\text { Light weight sands of four different } \\
\text { types in four different volume fractions } \\
\text { (V, OB0, OB1 and OB2) }(\text { vol\%) }\end{array}$ \\
\hline 100 & 62 & $10,14,20$ and 27
\end{tabular}

Note: Cellulose powder of $1.4 \%$ by weight of water was used in the mix

hybrid fiber composites can be seen by comparing Tables 6 and 7. It can be noticed that the use of light weight sands reduced the workability slightly but increased the air content significantly. The high air content in series 6 can be attributed to the high volume fraction of long PVA fibers.

\subsection{Flexural responses of mono fiber composites}

The load-CMOD curves presented in this paper are average of at least three specimens. Figures 4 and 5 show the load-CMOD curves for mono fiber composites. The composites with thinner PVA fibers
Table 6 Flow and air content of hybrid fiber composites containing normal silica sand

\begin{tabular}{llll}
\hline Series & & Flow $(\mathrm{mm} \times \mathrm{mm})$ & Air content $(\%)$ \\
\hline 3 & a & $165 \times 170$ & 5.7 \\
& b & $160 \times 165$ & 5.5 \\
& c & $155 \times 160$ & 5.6 \\
& d & $205 \times 205$ & 5.3 \\
& e & $170 \times 175$ & 5.4 \\
4 & a & $165 \times 163$ & 5.5 \\
& b & $160 \times 155$ & 5.5 \\
& c & $170 \times 165$ & 5.5 \\
& d & $165 \times 170$ & 6.0 \\
& e & $152 \times 152$ & 9.2 \\
5 & a & $170 \times 180$ & 4.7 \\
& b & $175 \times 170$ & 4.3 \\
& c & $160 \times 158$ & 5.3 \\
6 & a & $140 \times 146$ & 14.6 \\
& b & $142 \times 142$ & 15.5 \\
& c & $147 \times 145$ & $20+$ \\
\hline
\end{tabular}

show high flexural load but small CMOD capacity. On the other hand, the composite with thicker PVA fibers show low flexural load but large CMOD capacity. The higher ultimate load achieved with the thinner PVA fiber is due to its higher modulus compared with thicker PVA fiber. The higher ultimate load achieved with thinner PVA fiber is also due to the smaller size and higher interfacial area, which increases the maximum load that can be transferred to the fiber. On the other hand, the larger CMOD, thereby higher ductility, for the thicker PVA 
Table 7 Flow and air content of light weight hybrid fiber composites containing $2 \%$ thicker PVA fiber (12 mm) and $1 \%$ thinner PVA fiber $(6 \mathrm{~mm})$

\begin{tabular}{|c|c|c|c|c|c|c|c|c|}
\hline \multirow[t]{3}{*}{ Type of light weight sand } & \multicolumn{4}{|c|}{ Flow $(\mathrm{mm} \times \mathrm{mm})$} & \multicolumn{4}{|c|}{ Air content $(\%)$} \\
\hline & \multicolumn{4}{|c|}{ Sand volume fractions } & \multicolumn{4}{|c|}{ Sand volume fractions } \\
\hline & $10 \%$ & $14 \%$ & $20 \%$ & $27 \%$ & $10 \%$ & $14 \%$ & $20 \%$ & $27 \%$ \\
\hline OB0 & $157 \times 158$ & $155 \times 159$ & $158 \times 157$ & $157 \times 160$ & 13.8 & 17.9 & 18.2 & $20+$ \\
\hline OB1 & $155 \times 156$ & $155 \times 154$ & $155 \times 151$ & $140 \times 140$ & $20+$ & $20+$ & $20+$ & $20+$ \\
\hline OB2 & $147 \times 148$ & $146 \times 147$ & $149 \times 152$ & $136 \times 140$ & $20+$ & $20+$ & $20+$ & $20+$ \\
\hline $\mathrm{V}$ & $162 \times 162$ & $152 \times 158$ & $145 \times 155$ & $142 \times 140$ & 12.5 & 13.2 & 13.7 & 18.0 \\
\hline
\end{tabular}

Fig. 4 Flexural loadCMOD curves for mono fiber composites containing thinner PVA fibers
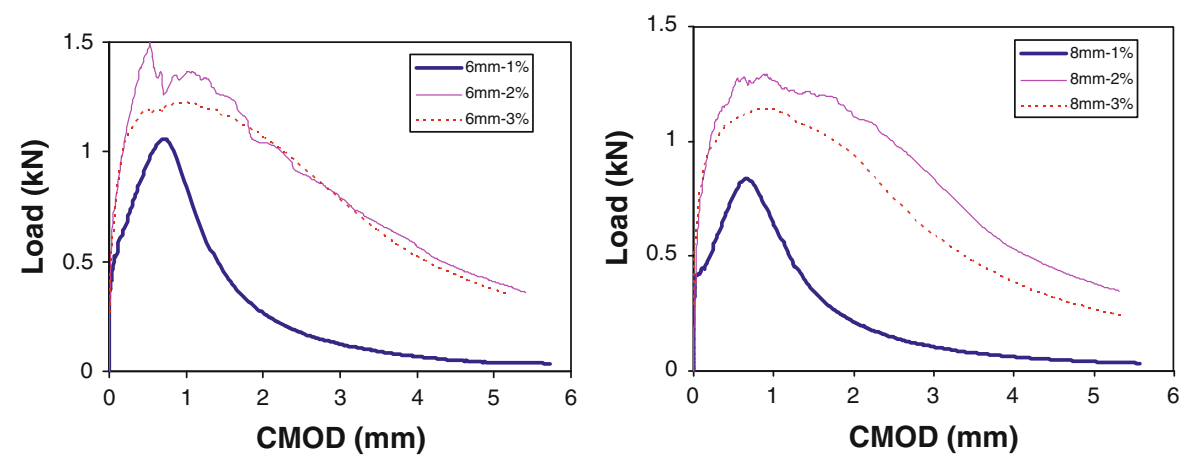

Fig. 5 Flexural loadCMOD curves for mono fiber composites containing thicker PVA fibers

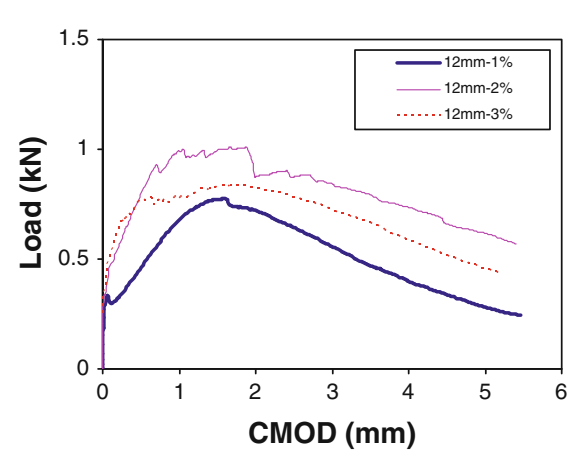

fibers is due to its low modulus and long length. By looking into Figs. 4 and 5 it can be noticed that the load-CMOD behavior of mono fiber composites is improved by increasing the fiber contents. However, at $3 \%$ fiber content the behavior did not improved but rather a reduction in load carrying capacity is observed and could be attributed to the poor dispersion of fibers due to high fiber content.

\subsection{Reinforcing mechanism of hybrid fibers}

Figure 6 shows the load-CMOD curves of mono fiber composites containing $1 \%$ (by volume) thinner PVA fibers of $6 \mathrm{~mm}$ length and 1\% thicker PVA fibers of $12 \mathrm{~mm}$ length. In the same figure the load-CMOD curve for hybrid fiber composites containing both $1 \%$ thinner PVA fibers of $6 \mathrm{~mm}$ length and $1 \%$ thicker PVA fibers of $12 \mathrm{~mm}$ length is also shown. The effects of hybrid reinforcement can be observed by comparing the load-CMOD curves of mono and hybrid fiber composites. This figure shows that if short micro fiber of higher modulus (6 mm long) is added to the composite containing lower modulus long macro fiber (12 $\mathrm{mm}$ long) the first crack strength and ultimate strength are increased significantly (compare curve "B" with curve "C"). The micro 


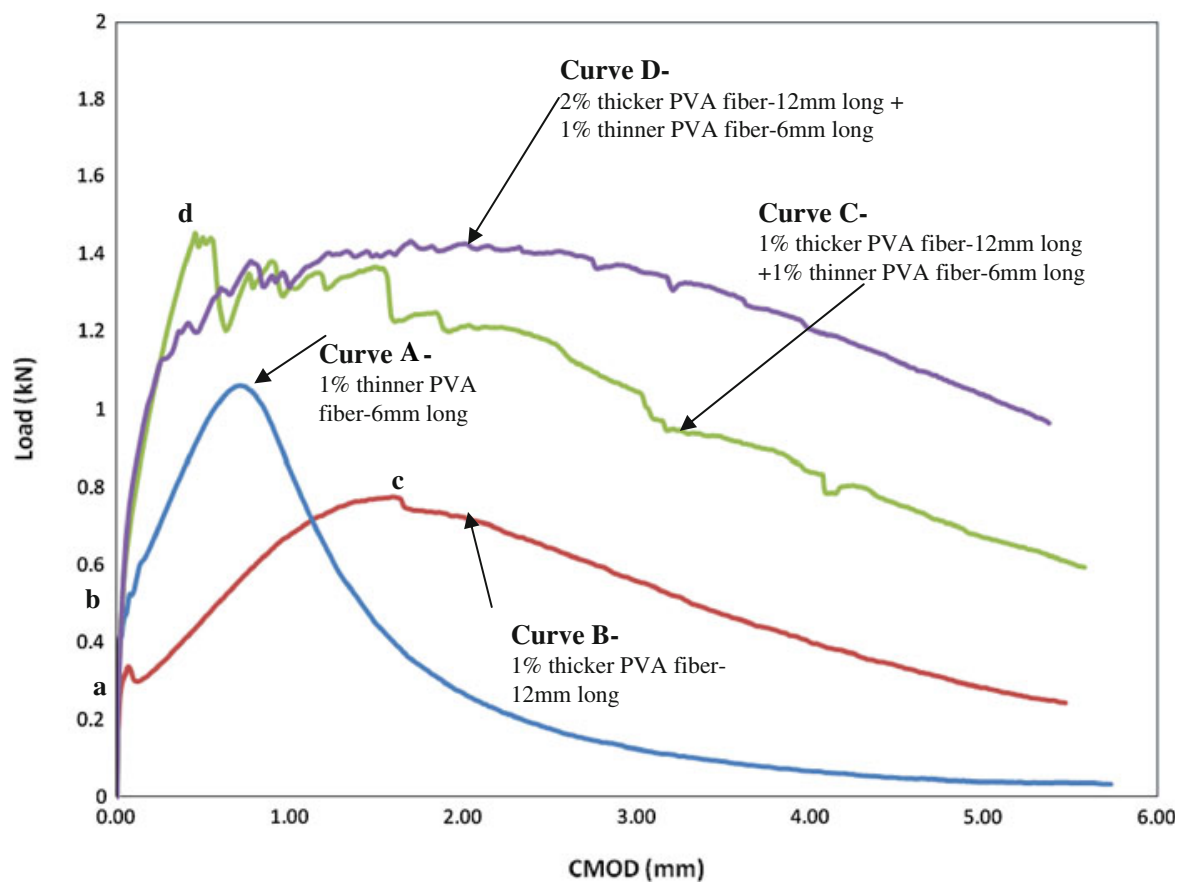

Fig. 6 Influence of hybrid fibers on the flexural behavior of cementitious composites

fibers contributed in two ways. First, it bridged the micro cracks and improved the toughness of the matrix thereby increased the first crack strength (compare point "a" with point "b"). Secondly, due to its higher modulus the ultimate strength of hybrid fiber composites is improved (compare point "c" with point "d"). The scenario is different when macro fibers are added (compare curve " $\mathrm{A}$ " with curve "C"). It shows that the ultimate strength is improved but the most significant improvement is the ductility. Because of its longer length it bridged the big cracks and improved the ductility. However, this hybrid composite did not show the strain hardening and multiple cracking behavior. The absence of strain hardening behavior and multiple cracks in this composite could be due to lower content of fibers than that of critical fiber content. And this can be confirmed by observing curve " $\mathrm{D}$ " where the volume fractions of low modulus macro PVA fiber is increased and the composite exhibited strain hardening behavior. This suggests the existence of a minimum amount of fibers in the composite for strain hardening and multiple cracking behavior and are discussed in the next section.

\subsection{Flexural responses of hybrid fiber composites}

The load-CMOD curves for hybrid fiber composites are shown in Figs. 7, 8, 9, and 10. Figure 7 shows the load-CMOD curves for hybrid fiber composites containing $1 \%$ thicker PVA fibers of $12 \mathrm{~mm}$ length together with $1 \%$ thinner PVA fibers of $6 \mathrm{~mm}, 8 \mathrm{~mm}$ and $12 \mathrm{~mm}$ lengths. The hybrid fiber composites do not show strain hardening behavior and the CMOD at peak load is also very small. A slightly improved behavior is observed when the length of thicker PVA fiber is increased from 12 to $24 \mathrm{~mm}$ (Fig. 8). This could be due to longer length of thicker fibers in the later case. By increasing the volume fraction of thicker fibers (both $12 \mathrm{~mm}$ and $24 \mathrm{~mm}$ long) from 1 to $2 \%$ in the hybrid composites the ductility is improved significantly and the results are shown in Figs. 9 and 10. By comparing the results in Fig. 10 it can be seen that the strain hardening behavior is sensitive to the length of thinner PVA fiber when combined with $2 \%$ thicker PVA fiber of $24 \mathrm{~mm}$ length. The inferior performance of hybrid composite containing 2\% thicker PVA fiber of $24 \mathrm{~mm}$ length and $1 \%$ thinner PVA fiber of $12 \mathrm{~mm}$ length compared 


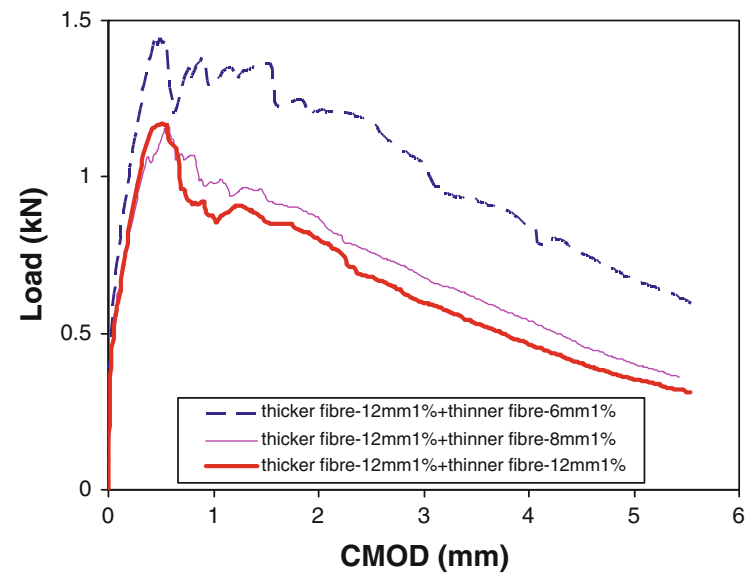

Fig. 7 Flexural load-CMOD curves for hybrid fiber composites containing $1 \%$ thicker PVA fiber of $12 \mathrm{~mm}$ long and $1 \%$ thinner PVA fiber of different length

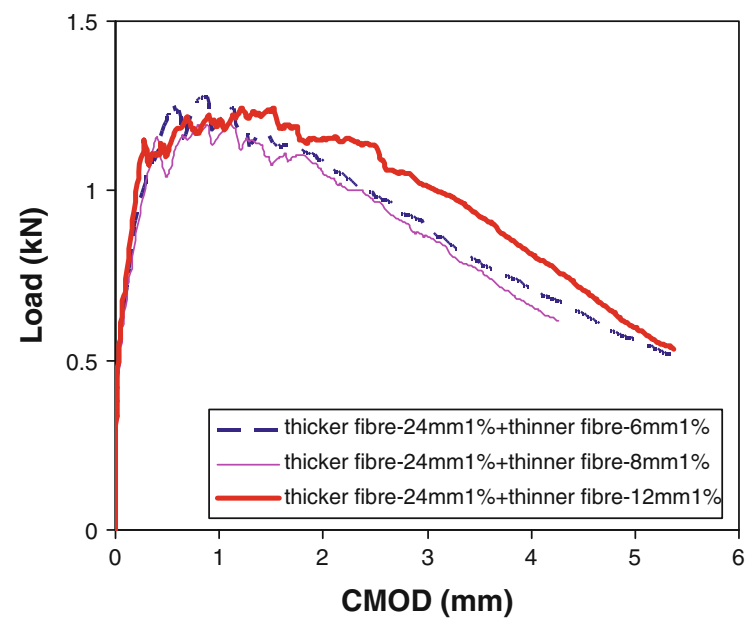

Fig. 8 Flexural load-CMOD curves for hybrid fiber composites containing $1 \%$ thicker PVA fiber of $24 \mathrm{~mm}$ long and $1 \%$ thinner PVA fiber of different length

to other two composites (such as $2 \%$ thicker PVA fiber of $24 \mathrm{~mm}$ length $+1 \%$ thinner PVA fiber of $6 \mathrm{~mm}$ length and 2\% thicker PVA fiber of $24 \mathrm{~mm}$ length $+1 \%$ thinner PVA fiber of $8 \mathrm{~mm}$ length) could be attributed as the poor dispersion of $12 \mathrm{~mm}$ long thinner PVA fibers with $24 \mathrm{~mm}$ long thicker PVA fibers in the former case. The CMOD as large as 2-3 $\mathrm{mm}$ at peak load is achieved in those hybrid composites. The composites also showed multiple cracks (Fig. 11). However, if the volume fraction of thinner PVA fibers in the hybrid fiber composites is increased no significant improvement in terms of

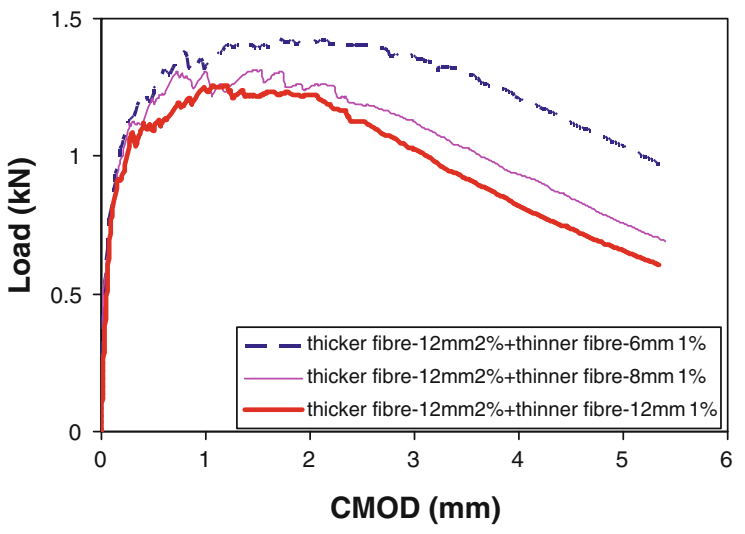

Fig. 9 Flexural load-CMOD curves for hybrid fiber composites containing $2 \%$ thicker PVA fiber of $12 \mathrm{~mm}$ long and $1 \%$ thinner PVA fiber of different length

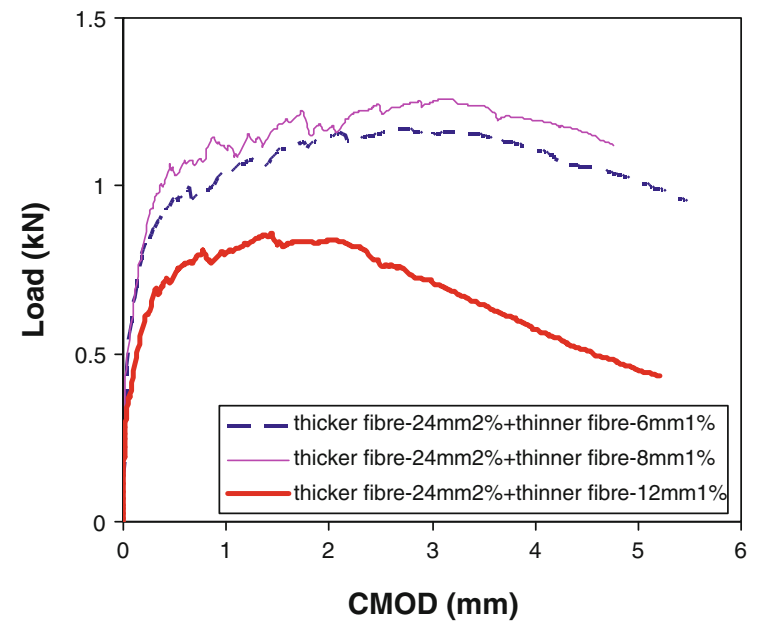

Fig. 10 Flexural load-CMOD curves for hybrid fiber composites containing 2\% thicker PVA fiber of $24 \mathrm{~mm}$ long and $1 \%$ thinner PVA fiber of different length

strain hardening behavior is observed. In Fig. 12 the load-CMOD curves of hybrid fiber composites containing $1 \%$ thicker PVA fibers of $12 \mathrm{~mm}$ length together with different volume fractions of thinner PVA fibers of $6 \mathrm{~mm}$ length (such as, 1\%, 1.5\% and $2 \%$ ) are shown. It can be seen from this figure that the increase of volume fractions of thinner PVA fibers of $6 \mathrm{~mm}$ length does not significantly improved the strain hardening behavior. This could be due to the fact that the thinner PVA fiber is short and of high modulus. However, the scenario is different when the volume fraction of thicker PVA fibers of $12 \mathrm{~mm}$ 

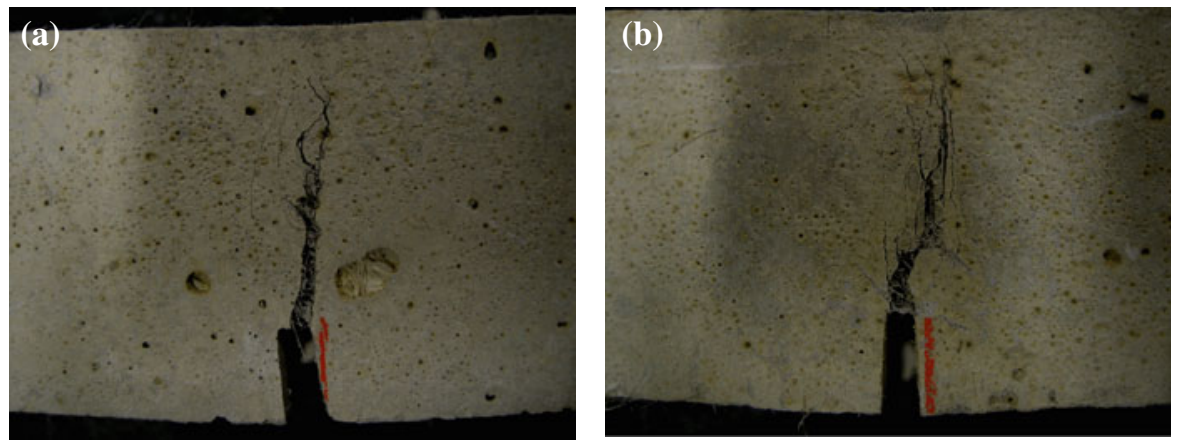

Fig. 11 Typical multiple cracking behavior of hybrid fiber composites containing normal silica sand. a 2\% thicker PVA fiber $(12 \mathrm{~mm})$ and $1 \%$ thinner PVA fiber $(6 \mathrm{~mm})$. b $2 \%$ thicker PVA fiber $(24 \mathrm{~mm})$ and $1 \%$ thinner PVA fiber $(6 \mathrm{~mm})$

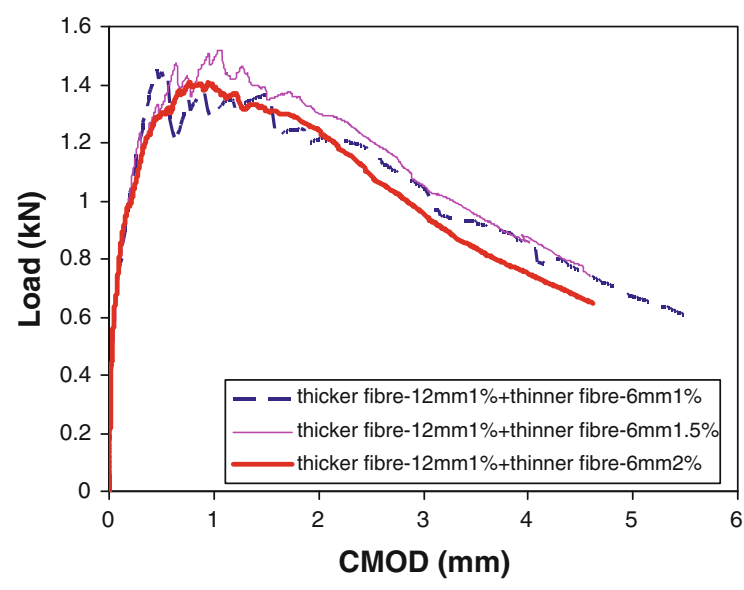

Fig. 12 Flexural load-CMOD curves for hybrid fiber composites containing $1 \%$ thicker PVA fiber of $12 \mathrm{~mm}$ length and different volume fractions of thinner PVA fiber of $6 \mathrm{~mm}$ length

length is increased. Figure 13 shows that if the volume fraction of thicker PVA fibers of $12 \mathrm{~mm}$ length is increased from 1 to $1.5 \%$ the strain hardening behavior can be achieved and at a volume fraction of $2 \%$ clear indication of strain hardening behavior is observed with large CMOD capacity at peak load. This suggest that a minimum volume fraction of a certain type of fiber is required in hybrid composites for the design of strain hardening behavior with considerable ductility where as the use of another type of fiber is required for the improvement of ultimate strength of the composite. In this study, within the fibers varieties studied, the thicker PVA fibers of $12 \mathrm{~mm}$ length and modulus of elasticity of $25 \mathrm{GPa}$ with volume fraction between 1.5 and $2 \%$, is the main fiber for the design of strain hardening behavior with large ductility whereas the thinner PVA fibers of $6 \mathrm{~mm}$ length and modulus of elasticity

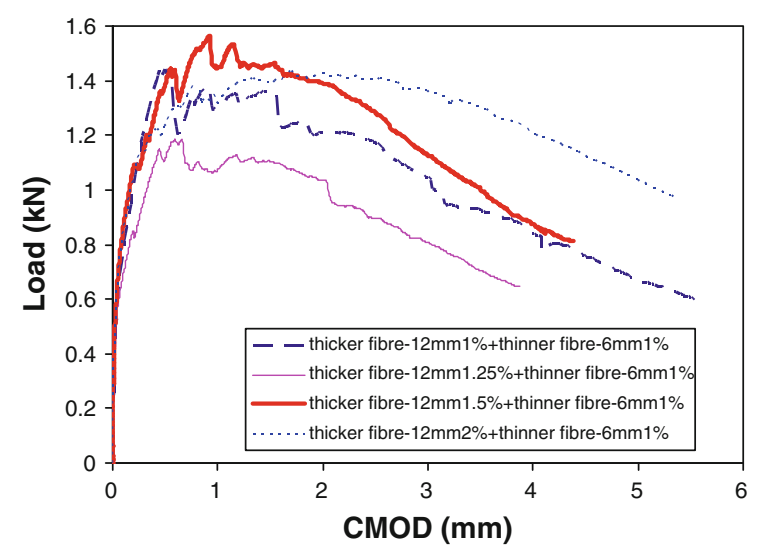

Fig. 13 Flexural load-CMOD curves for hybrid fiber composites containing $1 \%$ thinner PVA fiber of $6 \mathrm{~mm}$ length and different volume fractions of thicker PVA fiber of $12 \mathrm{~mm}$ length

of $40 \mathrm{GPa}$, contributed in the improvement of ultimate strength.

Both hybrid fiber composites containing 2\% thicker PVA fibers of $12 \mathrm{~mm}$ length together with $1 \%$ thinner PVA fibers of $6 \mathrm{~mm}$ length and 2\% thicker PVA fibers of $24 \mathrm{~mm}$ length together with $1 \%$ thinner PVA fibers of $6 \mathrm{~mm}$ length exhibited the best performance in terms of largest CMOD at peak load among all hybrid composites in the first part of this study and were used in the second part of this study.

\subsection{Flexural responses of hybrid fiber composites containing light weight sands}

The effects of different types of light weight sands on the strain hardening and multiple cracking behavior of hybrid fiber composites are also evaluated in this study. Four different types of light weight sands (i.e. V, OB0, 
OB1 and $\mathrm{OB} 2$ ) in four different volume fractions $(10 \%, 14 \%, 20 \%$ and $27 \%)$ were used in the development of light weight hybrid composites. Figure 14 shows the load-CMOD curves for hybrid fiber composite containing 2\% thicker PVA fibers of $12 \mathrm{~mm}$ length together with $1 \%$ thinner PVA fibers of $6 \mathrm{~mm}$ length and different light weight sands in different volume fractions. This figure shows that the ultimate load and CMOD at peak load for light weight hybrid fiber composites containing $10 \%$ and $14 \%$ light weight sand (by volume) are almost same for specimens with same sand type. A slight increase in ultimate load can be observed in hybrid fiber composites containing $20 \%$ and $27 \%$ light weight sand. This could be due to the higher amount of sand used in those composites compared to that containing $10 \%$ and $14 \%$. A similar trend is also observed in the hybrid fiber composite containing 2\% thicker PVA fiber of $24 \mathrm{~mm}$ length together with $1 \%$ thinner PVA fiber of $6 \mathrm{~mm}$ length (Fig. 15). However, the composites containing "V" and "OB0" type light weight sand exhibited higher ultimate load than those containing "OB1" and "OB2" type light weight sand. The low ultimate loads in hybrid composites containing "OB1" and "OB2" type light weight sand can be attributed to the higher amount of air content in those composites (see Table 7). All light weight hybrid fiber composites exhibited multiple cracks and are shown in Figs. 16 and 17. By comparing Figs. 9 and 14 it can be noticed that the hybrid fiber composite containing normal silica sand exhibited a higher ultimate load than the specimens containing light weight sands. This can be attributed to the higher volume fractions of normal silica sand used in those composites compared to light weight sand used in the hybrid fiber composites [21]. However, the CMOD at peak load of light weight hybrid fiber composites are comparable with composites containing normal silica sand.

The strain hardening and multiple cracking behavior of light weight hybrid fiber composites is further characterized by the ratio of complementary energy $\left(J_{\mathrm{b}}{ }^{\prime}\right)$ to crack tip fracture toughness $\left(J_{\text {tip }}\right)$. Complementary energy $\left(J_{\mathrm{b}}{ }^{\prime}\right)$ of fiber reinforced composites is represented by the area to the left of the load-CMOD curve up to the peak load, whereas crack tip fracture toughness $\left(J_{\text {tip }}\right)$ is represented by the area to the left of the load-CMOD curve up to load at steady state cracking state (Fig. 18). Steady state cracking occurs when a matrix crack propagate steadily at essentially constant external load and at essentially constant crack
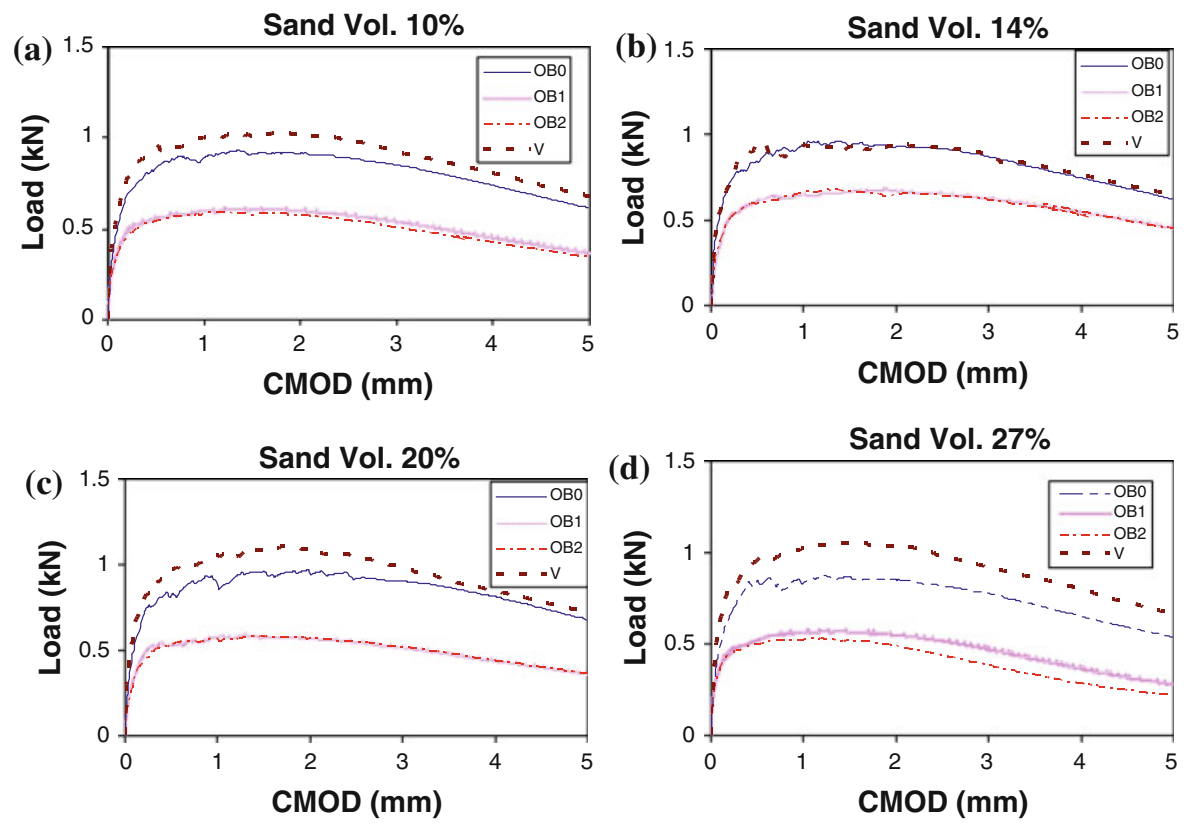

Fig. 14 Flexural load-CMOD curves for hybrid fiber composites containing 2\% thicker PVA fiber (12 mm) and 1\% thinner PVA fiber $(6 \mathrm{~mm})$ and different light weight sands with different volume fractions

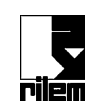


opening except near crack tip region. In fiber reinforced composites, due to the bridging action of fibers, the width of crack can be considered almost constant during propagation of cracks except the crack tip region. In this study the first cracking load is considered

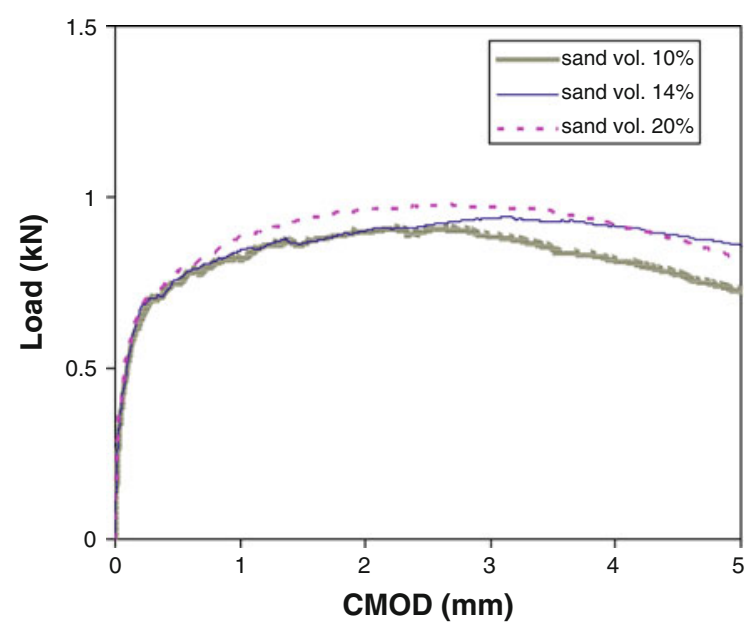

Fig. 15 Flexural load-CMOD curves for hybrid fiber composites containing $2 \%$ thicker PVA fiber $(24 \mathrm{~mm})$ together with $1 \%$ thinner PVA fiber $(6 \mathrm{~mm})$ and OB0 type light weight sand as the steady state cracking load. According to Kanda and $\mathrm{Li}$ [1] the ratio $J_{\mathrm{b}}{ }^{\prime} / J_{\text {tip }}$ equal to or greater than 3 is necessary to achieve saturated multiple cracking in fiber reinforced cementitious composites. The ratio $J_{\mathrm{b}}{ }^{\prime} /$ $J_{\text {tip }}$ calculated from the load-CMOD curves for light weight hybrid fiber composites containing $2 \%$ thicker PVA fibers of $12 \mathrm{~mm}$ length and $1 \%$ thinner PVA fibers of $6 \mathrm{~mm}$ length are summarized in Table 8 . Based on the above criteria, it can be seen from the table that almost all light weight hybrid fiber composites, except in some cases where higher volume fractions of light weight sands were used, sufficiently meet the multiple cracking requirement, that is $\left(J_{\mathrm{b}}{ }^{\prime} / J_{\text {tip }}\right) \geq 3$ and can be termed as strain hardening type materials.

The unit weight of hybrid fiber composites containing normal silica sand and light weight sands are summarized in Table 9. It can be seen from the table that the light weight hybrid fiber composites are about $22-38 \%$ lighter than that containing normal silica sand. Because of their lighter weight and strain hardening behavior these materials will have potential for certain structural applications, such as, better durability in beams/columns/slabs in RC building, repair/retrofitting of damaged RC structures due to its lightweight and strain hardening properties, etc.
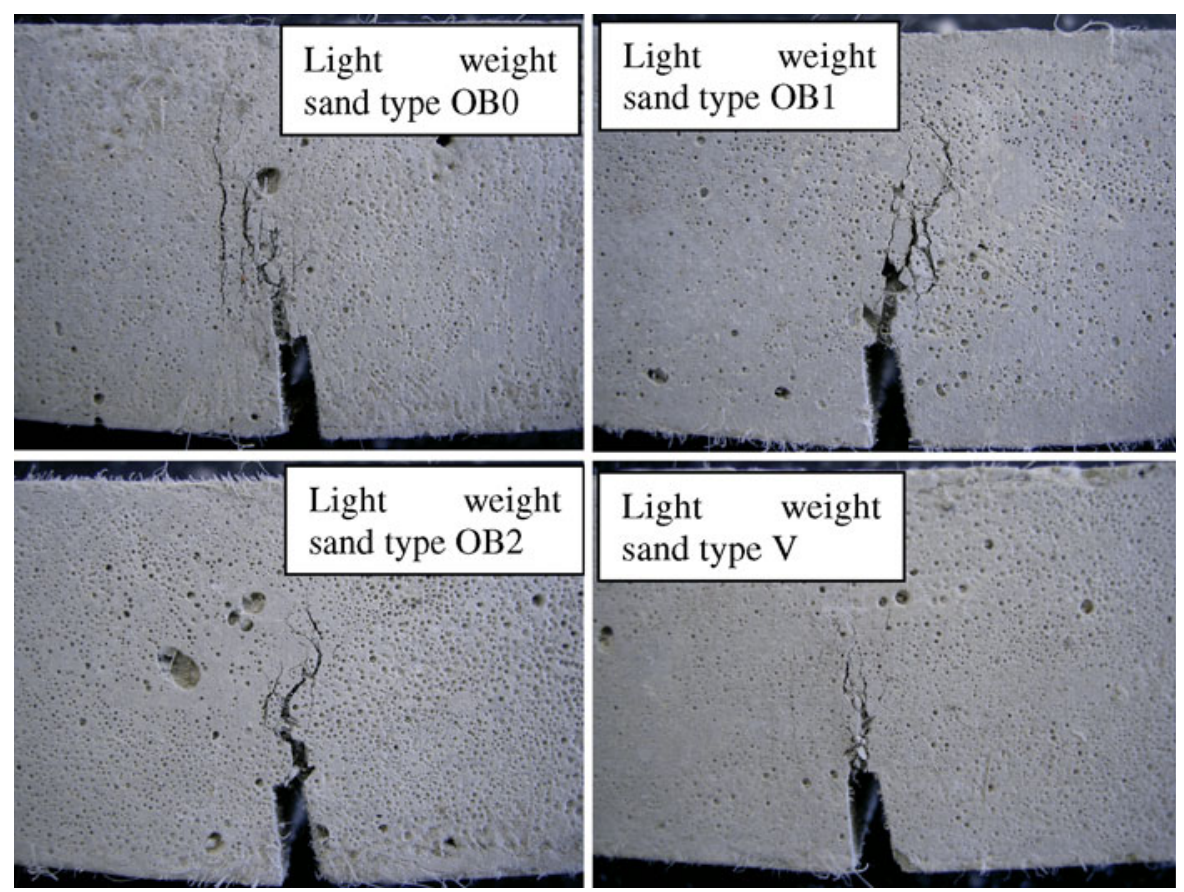

Fig. 16 Typical multiple cracking behavior of light weight hybrid fiber composites containing 2\% thicker PVA fiber (12 mm) and $1 \%$ thinner PVA fiber $(6 \mathrm{~mm})$ with different types of light weight sands of $10 \%$ by volume 

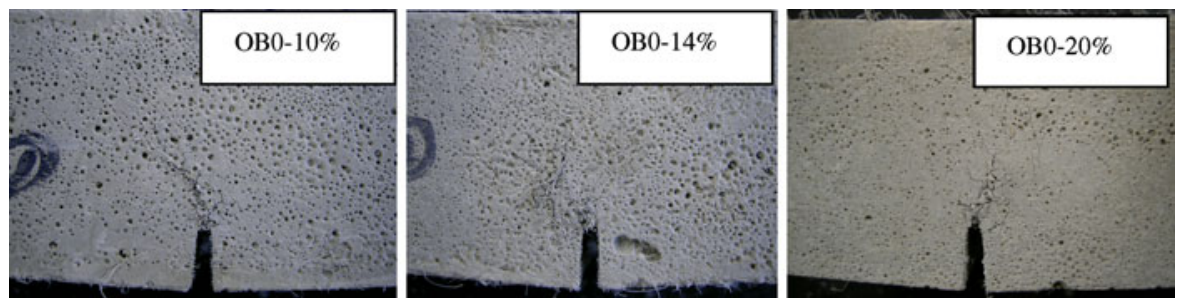

Fig. 17 Typical multiple cracking behavior of light weight hybrid fiber composites containing 2\% thicker PVA fiber (12 mm) and $1 \%$ thinner PVA fiber $(6 \mathrm{~mm})$ with OB0 type light weight sands of $10 \%, 14 \%$ and $20 \%$ by volume, respectively

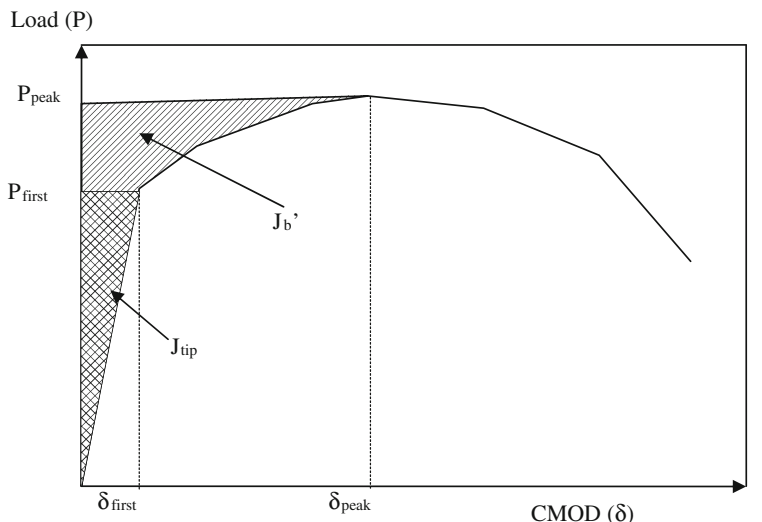

Fig. 18 Complementary energy $\left(J_{\mathrm{b}}{ }^{\prime}\right)$ and crack tip fracture toughness $\left(J_{\text {tip }}\right)$ of fiber reinforced composites (after, Kanda and $\mathrm{Li}[1])$

Table 8 Toughness ratios of light weight hybrid fiber composites containing $2 \%$ thicker PVA fiber $(12 \mathrm{~mm})$ and $1 \%$ thinner PVA fiber $(6 \mathrm{~mm})$

\begin{tabular}{lllll}
\hline \multirow{2}{*}{$\begin{array}{l}\text { Light weight } \\
\text { sand type }\end{array}$} & \multicolumn{4}{c}{ Volume fractions of light weight sands } \\
\cline { 2 - 5 } & $10 \%$ & $14 \%$ & $20 \%$ & $27 \%$ \\
\hline OB0 & 3.6 & 3.6 & 2.8 & 3.8 \\
OB1 & 4.3 & 3.3 & 2.6 & 2.8 \\
OB2 & 4.2 & 3.0 & 4.3 & 2.8 \\
V & 4.1 & 3.1 & 3.2 & 3.6 \\
\hline
\end{tabular}

\section{Conclusions}

Experimental results on the strain hardening and multiple cracking behavior of two different types of PVA fiber reinforced cementitious composites under bending are reported. The composite containing $2 \%$ thicker PVA fibers of $12 \mathrm{~mm}$ length together with $1 \%$ thinner PVA fibers of $6 \mathrm{~mm}$ length and the composite
Table 9 Unit weight of light weight hybrid fiber composites containing 2\% thicker PVA fiber $(12 \mathrm{~mm})$ and $1 \%$ thinner PVA fiber $(6 \mathrm{~mm})$

Light weight Unit weight of light weight hybrid composites sand type $\left(\mathrm{gm} / \mathrm{cm}^{3}\right)$

\begin{tabular}{lllll} 
& \multicolumn{3}{l}{ Sand volume fractions } \\
\cline { 2 - 5 } & $10 \%$ & $14 \%$ & $20 \%$ & $27 \%$ \\
\hline OB0 & 1.5 & 1.4 & 1.4 & 1.2 \\
OB1 & 1.3 & 1.2 & 1.1 & 1.0 \\
OB2 & 1.3 & 1.2 & 1.1 & 1.1 \\
V & 1.4 & 1.4 & 1.3 & 1.3 \\
\hline
\end{tabular}

Note: Unit weight of hybrid composites with normal silica sand $=1.8 \mathrm{gm} / \mathrm{cm}^{3}$

containing 2\% thicker PVA fibers of $24 \mathrm{~mm}$ length together with $1 \%$ thinner PVA fibers of $6 \mathrm{~mm}$ length showed the best performance in terms of highest ultimate load, largest CMOD and multiple cracking behavior. Strain hardening behavior in light weight hybrid PVA fibers reinforced cementitious composites is also achieved. The composites containing finer light weight sands exhibited higher ultimate load than those containing coarser light weight sands. It is also observed that the light weight hybrid fiber composites exhibited lower ultimate load than that containing normal silica sand but the CMOD at peak load of light weight hybrid fiber composites is comparable to composites containing normal silica sand.

Acknowledgments The first author would like to acknowledge the financial assistance in terms of post-doctoral fellowship from the Japan Society for Promotion of Science (JSPS). Authors acknowledge the assistance of Mr. Seisuke Suzuki in the experimental work. Grateful acknowledgement is also due to Kuraray Co. Ltd. of Japan for supplying the PVA fibers and Mr. Tsuyoshi Kubota of Saeki Co. Ltd. for supplying other materials. 


\section{References}

1. Kanda T, Li VC (1999) New micromechanics design theory for pseudo strain hardening cementitious composites. J Eng Mech ASCE 125(4):373-381

2. Kanda T, Lin Z, Li VC (2000) Tensile stress-strain modeling of pseudo strain-hardening cementitious composite. J Mater Civil Eng ASCE 12(2):147-156

3. Li VC, Wang S, Wu C (2001) Tensile strain hardening behavior of polyvinyl alcohol engineered cementitious composites (PVA-ECC). ACI Mater J 98(6):483-492

4. Li VC, Wu HC, Maalej M, Mishra DK, Hashida T (1996) Tensile behavior of engineered cementitious composites with discontinuous random steel fibers. J Am Ceram Soc 79(1):74-78

5. Kanda T, Li VC (2006) Practical design criteria for saturated pseudo strain hardening behavior in ECC. J Adv Concrete Technol 4(1):59-72

6. Li VC (2003) On engineered cementitious composites. J Adv Concrete Technol 1(3):215-230

7. Ahmed SFU, Maalej M (2009) Tensile strain hardening behaviour of hybrid steel-polyethylene fibre reinforced cementitious composites. J Construct Build Mater 23(1):pp.96-pp106

8. Ahmed SFU, Maalej M, Paramasivam P (2007) Analytical model for tensile strain hardening and multiple cracking behavior of hybrid fiber engineered cementitious composites. ASCE J Mater Civil Eng 19(7):527-539

9. Kawamata A, Mihashi H, Fukuyama H (2002) Material design of hybrid fiber reinforced cementitious composites. J Adv Concrete Technol 1(3):283-290

10. Ahmed SFU, Maalej M, Paramasivam P (2007) Flexural responses of hybrid steel-polyethylene fiber reinforced cement composites containing high volume fly ash. J Construct Build Mater 21(5):1088-1097
11. Rossi P (2000) Ultra high performance fiber reinforced concrete: an overview. In: Rossi P, Chanvillard G (eds) Proceedings of the 5th international RILEM symposium, France, pp 87-100

12. Banthia N, Nandakumar N (2003) Crack growth resistance of hybrid fiber reinforced cement composites. Cement Concrete Compos 25:3-9

13. Nehdi M, Ladanchuk JD (2004) Fiber synergy in fiber reinforced self consolidating concrete. ACI Mater J 101(6):508-517

14. Lawler JS, Zampini D, Shah SP (2005) Micro-fiber and macro-fiber hybrid fiber reinforced concrete. ASCE J Mater Civil Eng 17(5):595-604

15. Banthia N, Moncef A, Chokri K, Sheng J (1994) Microfiber reinforced cement composites. I: Uniaxial tensile response. Can J Civil Eng 21(6):999-1010

16. Oh BH, Shin KJ (2005) Cracking, ductility and durability characteristics of HPFRCC with various mixture proportions and fibers. Intl. workshop on HPFRCC in structural application, Hawaii, USA, pp 1-9

17. Banthia N, Soleimani SM (2005) Flexural response of hybrid fiber reinforced cementitious composites. ACI Mater J 102(6):382-389

18. Banthia N, Gupta R (2004) Hybrid fiber reinforced concrete (HyFRC): fiber synergy in high strength matrices. Mater Struct 37:707-716

19. Sorelli LG, Meda A, Plizzari GA (2005) Bending and uniaxial tensile tests on concrete reinforced with hybrid steel fibers. ASCE J Mater Civil Eng 17(1):519-527

20. Soroushian P, Tlili A, Abdulrahman A, Khan A (1993) Development and characterization of hybrid polyethylene fiber reinforced cement composites. ACI Mater J 90(2):182-190

21. Akkaya Y, Peled A, Picka JD, Shah SP (2000) Effect of sand addition on properties of fiber reinforced cement composites. ACI Mater J 97(3):393-400 